\title{
Does Opinion Leadership Increase the Followers on Twitter
}

\author{
Yoosun Hwang
}

\begin{abstract}
As an efficient channel of an information flow, Twitter is being paid more attention by opinion leaders. The present study investigated motivational effects of opinion leadership of Twitter users and the users' intentional process of increasing followers. On Twitter, information flows interpersonally by followers and larger number of followers helps to enhance the reach of opinion on mass public. Data were obtained through an online survey and Structural Equation Model was adopted for the analysis. First, the motivational trait of opinion leadership of Twitter users was examined. Then, the effect of opinion leadership of Twitter users on the intention of making followers group was explored. The results show that Twitter users' higher level of self-esteem positively affects higher level of users' opinion leadership. Opinion leadership of Twitter users positively predicts higher intention of forming larger followers group. The users' intention of social participation through information exchange was found to be positively associated with the intention of making larger number of followers mediating opinion leadership. Implications of the findings and meaning of followers on Twitter were discussed.
\end{abstract}

Index Terms-Information flow, opinion leadership. self-esteem, twitter.

\section{INTRODUCTION}

Advanced forms of Internet communication channels provide convenient communication methods between users who share common interests [1]. Especially, Twitter has generated substantially enthusiastic attention of late. Twitter has the ability to supply people with robust information with RT that enables a unique role of Twitter to spread information among mass public [2]-[6]. Due to the systems that help the efficient information flow, people with opinion leadership take pains to take advantage of these technical conveniences. Twitter gives people a chance to become a widely known figure if they can produce interesting and valuable information to attract the attention of the mass public.

Traditionally, opinion leadership has been thought to have more impact in Face-to-face settings [7], [8]. The "two-step flow" model, in this vein, emphasizes the role of opinion leaders who moderate information flow between mass media and community members [9]. Later, the "multi-step flow" model describes that information flows not only vertically but also horizontally, which adds the decentralization and openness to the information flow [10]-[13]. On Twitter, as

Manuscript received December 15, 2013; revised February 11, 2014.

Yoosun Hwang is with the Department of Journalism and Communication, Joongbu University, Daehakro 201 Chubu Geumsan Choongnam, South Korea (e-mail: yshwang@ joongbu.ac.kr). any users, regardless of their social status, can deliver useful information and receive others' attention, information flows horizontally as well as vertically. Regarding the information diffusion, having more followers are advantageous to the exertion of opinion leadership. Even though studies reveal that a large number of followers do not always guarantee power of information on Twitter [14], the diffusion of opinions or information is actually performed by followers on Twitter. Thus, some scholars focused on the number of followers and reteweets to indentify Twitter users' influences [15].

The scale of followers needs to be preceded for exerting opinion leadership on Twitter. The present study focused on verifying Twitter users' intention to attract larger size of followers. It is supposed that Twitter users, especially those seeking opinion leadership status, were still interested with the scale of followers on a cyberspace. In addition to this, to gain followers' attention by reducing their passivity is crucial to the exertion of opinion leadership [16]. The purpose of the current study is to explore the possibility and the process of opinion leadership on Twitter in the users' situation. This study first analyzed the motivational effect on Twitter users' opinion leadership. Then, it is contended that Twitter users with opinion leadership might be interested to raise the number of followers and be willing to make some effort to this end.

\section{LITERATURE REVIEW}

\section{A. Motivational Traits of Opinion Leadership on Twitter}

An opinion leader has been defined as "a person who exerts influence on the opinions of others" [17], Opinion leaders are known to serve as social models, and consequently to influence the attitudes of their followers [18]-[20]. It is also acknowledged that public opinion is formed by "opinion statements" that are constructed through opinion leaders' cues and information [21].

Scholars have identified several attributes that are commonly related to traits of opinion leadership. Both self-reliance and higher self-confidence are characteristics frequently found among individuals with opinion leadership [22], [23]. Chan and Misra ${ }^{24}$ argued that the willingness to stand out among a group and differentiate oneself from others in public might play a role in motivating successful dissemination of information to the mass public. Also, innovativeness [24], [25] and enthusiastic social activities [24], [26] have been described as traits of opinion leadership. Mediated communication settings can also be used as an appropriate virtual place to perform opinion leadership. 
Self-confident Twitter users could reveal themselves without restraint, post many tweets to diffuse their opinions, and interact vigorously with other users. These behaviors are consequently considered as displaying opinion leadership to followers on Twitter.

As for the motivational trait of opinion leadership, self-esteem has been conceptualized as one's evaluation of or attitude toward oneself and as feeling that one is good enough [27], [28]. High self-esteem, along with high confidence has been perceived as a precondition of effective leadership [29]. More specifically, self-esteem causes individuals' direct, straightforward, dominating, and assertive communication styles [30] and encourages active participation in communication [31]. While, lower self-esteem makes people engage in communication less frequently [32].

It is assumed that the individuals' intrapsychic traits continue to be exerted in the mediated communication settings. Thus, self-esteem could support individuals' capacity to better establish their opinion leadership over others on Twitter. Numerous studies have also found that the traits of opinion leadership during online interactions did not greatly differ from those that of offline settings [33], [34]. Hence, it is supposed that the relationship between self-esteem and opinion leadership would appear to be the same on Twitter. Thus, the following hypothesis is established.

H1. Self-esteem of Twitter users will positively predict a higher level of Twitter users' opinion leadership.

\section{B. Opinion Leadership and Followers on Twitter}

Regarding opinion leadership, it has been said that interpersonal communication had more persuasive power than messages delivered through mass media [9], [19]. Accordingly, distributing information through word-of-mouth communication is commonly considered more powerful and credible [24], [35]. Information flow on Twitter does not much differ from these interpersonal processes in daily social interactions. The openness of Twitter, due to the simple follow/unfollow process, enables users to easily flock to an opinion leaders' Twitter and subscribe to the information of interest. These spontaneously gathered followers are ready to hear and distribute what an opinion leader delivers through Twitter. Moreover, retweet (RT) expand the coverage of an opinion by allowing users to re-broadcast valuable information to their followers at one effort.

Any ordinary users other than real opinion leaders such as celebrities and politicians could take the position of opinion leader if only they were able to provide valuable information and gather more attention from the mass public on Twitter. Since the main role of an opinion leader is to propose an opinion and then influence others [17], [36], a considerable size of followers is important as a precondition of an efficient display of opinion leadership to public mass. Therefore, a Twitter user who has more followers could have more chance to widen the reach of an opinion and consequently enhance the interpersonal influence.

Studies have so far supported the importance of the number of followers. Opinion leadership was found to relate to the scale of their various social networks and the density of their social relations [23], [37]. Individuals who possess a high density of social relations can actively exchange information and consequently gain a position to disseminate their ideas among followers in a social network [38]. Given a large scale of followers, opinion leaders are likely to shape the followers' behaviors toward social issues [39]. On Twitter, too, more followers would be helpful for demonstrating opinion leadership. Following these notions, it is possible that Twitter users with opinion leadership may be concerned with about attracting followers. The following hypothesis can be brought:

H2. Twitter users' higher level of opinion leadership will positively predict Twitter users' intention to form a followers group on Twitter.

\section{Traits of Followers on Twitter and Impact of Information}

Unlike other interpersonal social-media networks, the participation of Twitter's personal tie does not always imply interpersonal intimacy [4]. In most cases, Twitter users can freely follow other users' Twitter without permission, and they may also "unfollow" that account at anytime. Due to its weak interpersonal ties, relationships within the Twitter world do not always entail reciprocal activities [40]. A large number of followers do not mean that the user has the same number of intimate friends on Twitter. Rather, the number of followers implies that that many people have had an interest in the user's Twitter. In other words, instead of interpersonal closeness, common interests or valuable information are more likely to have an effect on forming a network on Twitter.

Another trait of followers on Twitter is that they readily receive unilateral information or an agenda directly from opinion leaders. In fact, the top 10 percent of prolific Twitter users were found to generate over 90 percent of tweets [41], which illustrates that tweets tend to be produced by a small group of active opinion leaders. However, just having large scale of followers does not guarantee a meaningful level of attention from mass public. Simply to increase followers could not strengthen the impact of information - rather, to increase close attention to information is more crucial for the influence of opinion leadership [42]. Consequently, the following research question was proposed:

RQ1. How do Twitter users with opinion leadership try to attract attention of followers on Twitter and then strengthen their influence.

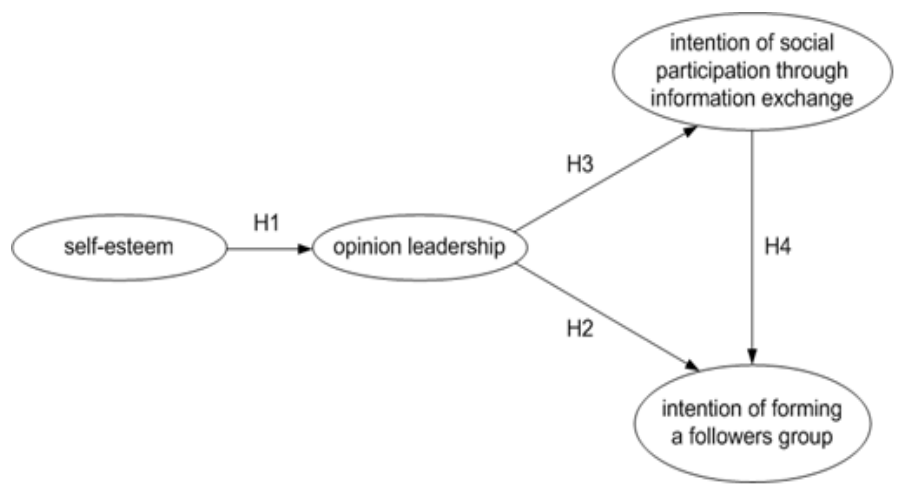

Fig. 1. Hypothesized mode. 


\section{Active Participation and Gathering Followers on Twitter}

Unlike other interpersonal when people are more concerned with topics, they are found to care less about the characteristics of the source [43], [44]. Instead, conversation about diverse social issues causes higher attention and participation [45]. Thus, on Twitter, any user who successfully creates consensus on a specific issue has strong probability to display opinion leadership. Chan \& Misra [24] contend that opinion leaders are eager to differentiate themselves from other community members by vigorously delivering information or opinions in a certain community group. People with higher opinion leadership had more interest in social issues, and participate more in their communities [23], [39], [46] and they are interested in developing social agendas [47]. For better positioning of opinion leadership, it has been shown that frequent contact with people, public speech, participation in discussion, and association with myriad social events are beneficial ${ }^{23}$. In this way, social participation is important for gaining others' understanding and control over personal, social, economic, and political forces [48].

Therefore, on a Twitter space, users with higher levels of opinion leadership could participate more in social interactions and then possibly display opinion leadership by properly posting or exchanging more tweets about important information and personal opinion. It has also been proved that ordinary Twitter users tend to engage in constant interactions on prolific users' Twitter accounts to interpret social experiences [40]. Thus, to involve in activities of the online community, especially on Twitter, might have the positive effects on stimulating others to contribute to a social issue by creating trust toward the users with opinion leadership. Thus, we suggest the following hypothesis:

H3. Twitter users' higher levels of opinion leadership will positively predict Twitter users' intention of social participation through information exchange on Twitter.

Social relation is one dimension of opinion leadership. Opinion leadership relates to the scale of the leaders' various social networks and the density of their social relations [37], [23]. Individuals who possess a high density of social relations can actively exchange information and, consequently, they gain an advantageous position from which to disseminate their ideas among the followers in a social network [38]. From these perspectives, how to form a social network position during social participation helps opinion leaders influence others [49].

Studies found that opinion leaders are likely to present unshared information to others and then deal with widely known information by discussing it in greater depth with mass audiences [50], [51]. Opinion leaders contact many people through various organizations and attend lots of social events [11], [23], due to which they are likely to shape the followers' behaviors toward social issues [39]. These previous findings suggest that opinion leaders tend to have communication among a wider range of people and exhibit opinion leadership over more followers. In fact, on Twitter, the activities of creating a social issue and participating in a discussion on it may trigger a larger scale of followers [52], which is related with the increase of opinion leadership. Thus, users with opinion leadership could enlarge or affect their followers group with an effort to continuously participate in current social issues by providing information on Twitter. So, the following hypothesis is suggested.

H4. Twitter users' intention of active social participation through information exchange on Twitter will positively predict Twitter users' intention to form a followers group on Twitter.

\section{METHOD}

\section{A. Sampling}

The sample included 396 respondents who were Twitter users. Respondents consisted of 242 males $(61.1 \%)$ and 154 females $(38.9 \%)$. The mean age was $30.78(S D=7.52)$ years with a range of 14 to 68 . Data were collected through an online survey on Twitter, from January 12 to January 19, 2010. The respondents voluntarily participated in the survey.

\section{B. Measurement}

Factor analysis for Twitter users' intentions

To find out twitter users' intention in using Twitter, a factor analysis was performed. Items that were found to be motivations for using new media were used [52]-[55]. Items about Twitter's unique properties (e.g., "Writing within 140 characters induces creative writing ability" and "Twitter users can form follower groups whose members share common interests") were adopted from earlier studies [56]. As a result, seven factors were extracted, which explained $56.14 \%$ of the total variance (see Table I).

\section{1) Intention of social participation through information exchange}

The first factor among the extracted seven factors was adopted for the scale of "social participation through information exchange." A five-point Likert scale ranging from $1=$ strongly disagree to $5=$ strongly agree was used. The mean of this factor is $3.80(S D=0.39)$.

\section{2) Intention of forming a followers group}

This scale was adopted from the second factor "forming a followers group" of the above extracted factors. The mean of this factor is $3.88(S D=0.85)$.

\section{3) Self-esteem}

Rosenberg's global-measurement [28] was used (e.g., "I feel that I have a number of good qualities."). A 5-point Likert scale ( $1=$ strongly disagree to $5=$ strongly agree $)$ was used (Cronbach's alpha $=0.84$ ).

\section{4) Opinion leadership}

The present study made use of Weimann's [49] Opinion leadership scale (e.g., "I like to take the lead when a group does things together."). A 5-point Likert scale ranging from 1 $=$ strongly disagree to $5=$ strongly agree was used, and the reliability was appropriate (Cronbach's alpha $=0.83$ ).

\section{RESUlts}

The data was analyzed using the SEM (Structural Equational Model). To minimize observation errors [57], 
[58], observed variables were randomly parceled into three for the latent variables of self-esteem and opinion leadership, and into four for the latent variables about users' intentions. The model offered an acceptable fit; $X^{2}(73, N=396)=$ $151.315, p=0.000, C F I=0.974, T L I=0.967$, and $R M S E A=$ 0.052 (see Fig. 2).

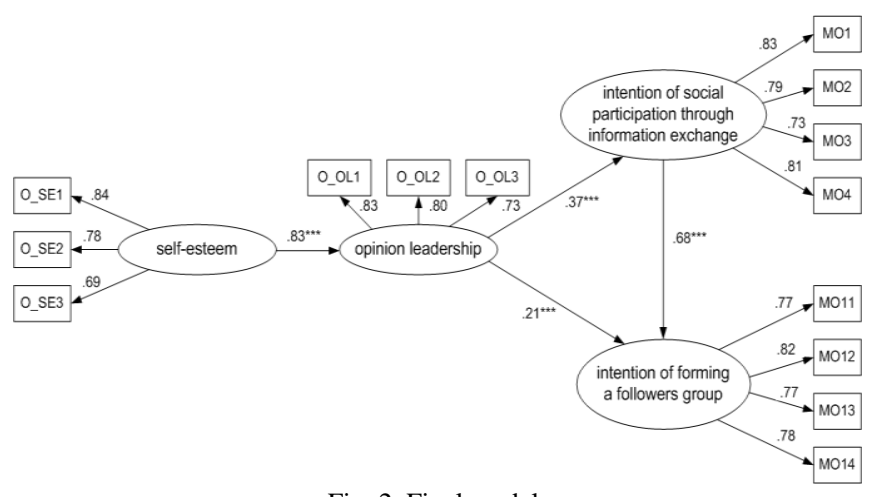

Fig. 2. Final model.

TABLE I: INTENTIONS OF TWITTER USE

\begin{tabular}{|c|c|c|c|c|c|c|c|}
\hline \multicolumn{6}{|c|}{ Factor 1 Social participation through information exchange } & \multicolumn{2}{|c|}{ Factor loading } \\
\hline \multicolumn{6}{|c|}{ Twitter helps me learn critical social issues. } & \multicolumn{2}{|c|}{0.735} \\
\hline \multicolumn{6}{|c|}{ I get interested in social issues through Twitter. } & \multicolumn{2}{|c|}{0.701} \\
\hline \multicolumn{6}{|c|}{ I can come in contact with various interpretations and explanations of social problems. } & \multicolumn{2}{|c|}{0.633} \\
\hline \multicolumn{6}{|c|}{ I can get professional knowledge and information. } & \multicolumn{2}{|c|}{0.594} \\
\hline \multicolumn{6}{|c|}{ I participate in discussions about social issues. } & \multicolumn{2}{|c|}{0.578} \\
\hline \multicolumn{6}{|c|}{ I can encounter diverse cultures through Twitter. } & \multicolumn{2}{|c|}{0.528} \\
\hline \multicolumn{6}{|c|}{ Twitter helps me understand other people. } & \multicolumn{2}{|c|}{0.522} \\
\hline \multicolumn{6}{|c|}{ I can exchange various opinions and information on Twitter. } & \multicolumn{2}{|c|}{0.515} \\
\hline \multicolumn{8}{|c|}{ Factor 2 Forming a followers group } \\
\hline \multicolumn{6}{|c|}{ I can easily participate in conversations among other Twitter users. } & \multicolumn{2}{|c|}{0.748} \\
\hline \multicolumn{6}{|c|}{ I can easily feel a bond with other twitter users. } & \multicolumn{2}{|c|}{0.658} \\
\hline \multicolumn{6}{|l|}{ I can have many followers. } & \multicolumn{2}{|c|}{0.654} \\
\hline \multicolumn{6}{|c|}{ Twitter helps me form certain follower groups that have the same interest as me. } & & \\
\hline I can mix with influential & & & & & & & \\
\hline I can get acquainted with 1 & neet elsev & & & & & & \\
\hline I can share important knov & & & & & & & \\
\hline Factor 3 Convenient use & n tool & & & & & & \\
\hline Services that are connecte & wittercol & c) make $\mathrm{i}$ & o use tw & & & & \\
\hline Twitter makes me to use o & Blogs, Yo & & & & & & \\
\hline Factor 4 Transferring in & & & & & & & \\
\hline Twitter delivers informatic & & & & & & & \\
\hline I can upload photos, video & itter. & & & & & & \\
\hline Factor 5 Relaxation and & & & & & & & \\
\hline Using Twitter helps in reli & & & & & & & \\
\hline Through twitter, I can forg & he everyc & & & & & & \\
\hline Twitter is good for killing & & & & & & & \\
\hline Twitter is fun and entertair & & & & & & & \\
\hline Factor 6 Writing private & & & & & & & \\
\hline I express my feelings and & & & & & & & \\
\hline I keep a record of my daily & & & & & & & \\
\hline Factor 7 Taking advanta & & & & & & & \\
\hline Writing within 140 words & vey my o & more cle & & & & & \\
\hline Writing within 140 words & riting. & & & & & & \\
\hline Factor & 1 & 2 & 3 & 4 & 5 & 6 & 7 \\
\hline Eigen value & 5.309 & 5.261 & 3.315 & 3.078 & 2.980 & 2.510 & 2.251 \\
\hline Variance (\%) & 12.065 & 11.956 & 7.533 & 6.996 & 6.773 & 5.705 & 5.115 \\
\hline Cumulative variance $(\%)$ & 12.065 & 24.021 & 31.555 & 38.551 & 45.323 & 51.028 & 56.143 \\
\hline Cronbach's $\alpha$ & 0.859 & 0.868 & 0.753 & 0.753 & 0.809 & 0.739 & 0.871 \\
\hline
\end{tabular}


Hypothesis 1 predicted that Twitter users' self-esteem would raise their opinion leadership. The data were consistent with this expectation $(\beta=0.83, p<0.000)$, demonstrating that individuals with higher self-esteem exhibited more opinion leadership on Twitter. Hypothesis 2 predicted that Twitter users' opinion leadership would enhance their intention of forming followers group on Twitter. As expected, Twitter users' opinion leadership was positively associated with the intention of making followers group $(\beta=0.21, p<0.000)$. Hypothesis 3 predicted that Twitter users' opinion leadership would result in their intention of social participation through information exchange on Twitter. The results supported the positive effect of opinion leadership $(\beta=0.37, p<0.000)$. Hypothesis 4 examined how Twitter users' intention of forming a followers group was influenced by their intention of social participation through information exchange. As expected, higher intention of social participation through information exchange was significantly associated with higher intention of forming a followers group on Twitter $(\beta=0.68, p<0.000)$. Twitter users who actively participate in social issues and create agendas on Twitter were likely to want to have more followers on their Twitter accounts. The squared multiple correlation of the intention of forming a followers group was acceptable $\left(R^{2}=0.61\right)$.

\section{DISCUSSION}

This study investigated several motivational traits of Twitter users with opinion leadership. It was supposed that Twitter users with opinion leadership would be concerned with making more followers who carefully listen to their information. Since the participants of the study are considered to be already active and motivated users, the study may reflect special features of Twitter's very enthusiastic users. However, the following implications can be drawn.

Twitter users' higher self-esteem was found to enhance their level of opinion leadership. The results support previous findings (in offline settings) that self-esteem could be a positive background for individuals' opinion leadership. Baumeister et al. [27] suggest that self-esteem is related with a motivational style of self-presentation and, thus, higher self-esteem leads to better performance with higher self-confidence [27], [59], [60]. Therefore, on Twitter, where users need to present themselves in the most appropriate way, individuals' self-esteem by promoting an intrapsychic self-assured attitude might be more crucial for a better display of opinion leadership. It has also been proven that one's offline traits are well reflected in the online interactions, which suggests the possibility of building trust and social reputation in online social media, Twitter.

Twitter users with higher opinion leadership were found to have a greater motivation to gather many followers who listen to their information. These users were also found to have a tendency to participate in active social interactions that could result in making more followers group on their Twitter account. To gather many followers plays an important role for an exertion of opinion leadership on
Twitter. Similarly, the extent and the degree of interpersonal contacts and personal ties are important aspects for the process of information flow10. Thus, these findings could explain the meaning of followers on Twitter. The followers' attentive responsiveness and active engagement is necessary. At the same time, these findings imply that Twitter has a potential as an earnest public sphere of discourse, spurring vigorous social interactions and deliberations led by the users with higher opinion leadership.

Twitter could work as a platform to gather social members under the same social issues. As the findings suggest, on Twitter, social issues and influential information seem to operate as moderators that invite an enormous portion of the public into the cyber-sphere; Twitter. During this process, opinion leadership plays a role in civic participation that goes beyond socioeconomic status, personal resources, or informational variables [61]. Then, the rest of the users, mostly followers, can select reasonable discussions and join the in-depth communication actively and spontaneously.

While people in the offline world are usually susceptible to an opinion leader's personal view, the followers on Twitter are open to various sources of information and they are more intellectually independent. Therefore, on Twitter, opinion leadership might be attributed to followers' interests. Followers of Twitter, together with opinion leaders, take part in creating important issues and disseminating information. Consequently, with this new media, opinion leadership could be efficiently performed and the conversion of passive followers to active participants could occur.

\section{REFERENCES}

[1] A. S. Acar and M. Polonsky, "Online social networks and insights into marketing communications," Journal of Internet Commerce, vol. 6, pp. 55-72, 2007.

[2] B. J. Jansen, M. Zhang, K. Sobel, and A. Chowdury, "Twitter power: tweets as electronic word of mouth," Journal of the American society for Information Science and Technology, vol. 60, pp. 2169-2188, 2009.

[3] R. E. Goldsmith and C. F. Hofacker, "Measuring consumer innovativeness," Journal of the Academy of Marketing Science, vol. 19, pp. 209-221, 1991.

[4] B. A. Huberman, D. M. Romero, and F. Wu. (2008). Social network that matter: Twitter under the microscope. [Online]. Available: http://arxiv.org/PS_cache/arxiv/pdf/0812/0812.1045v1.pdf

[5] J. Postman. (2008). Seven rules for establishing a corporate presence on Twitter. [Online]. Available: http://www.socialmediatoday.com/SMC/44452

[6] K. D. Sweetser. (2008). [Online] Available: http://www.kayesweetser.com

[7] C. Chen and P. Hernon, Information-Seeking: Assessing and Anticipating User Needs, New York: Neal_Schuman, 1982.

[8] B. Devin, M. Nilan, and T. Jacobson, "Improving predictions of information use: A comparison of predictor types in a health communication setting," in Communication Yearbook, M. Burgoon, Ed. Beverly Hills, CA: Sage, 1982, pp. 807-830.

[9] P. R. Lazarsfeld, B. Berelson, and H. Gaudet, The People's Choice: How the Voter Makes Up His Mind in a Presidential Campaign, New York: Columbia University Press, 1944.

[10] J. P. Robinson, "Interpersonal influence in election campaigns: Two-step flow hypotheses," Public Opinion Quarterly, vol. 40, 1976, pp. 304-319.

[11] V. Troldahl and R. V. Dam, "Face-to-face communications about major topics in the news," Public Opinion Quarterly, vol. 29, 1966, pp. 626-634.

[12] G. Weimann, "On the importance of marginality: One more step into the two-step flow of communication," American Sociological Review vol. 47, 1982, pp. 764-773. 
[13] C. Wright and M. Cantor, "The opinion seeker and avoider: steps beyond the opinion leader concept," Pacific Sociological Review, vol. 10, 1967, pp. 33-43.

[14] M. Cha, H. Haddadi, F. Benevenuto, and K. P. Gummadi, "Measuring user influence in Twitter: The million followers fallacy," in Proc. the 4th International AAAI Conference on Weblogs and Social Media, May 23-26, pp. 1-8, 2010.

[15] H. Kwak H, C. Lee, H. Park, and S. Moon, "What is Twitter, a social network or a news media?" in Proc. the 19th International Conference on World Wide Web, vol. 1, 2010

[16] D. M. Romero, W. Galuba, S. Asur and B. A. Huberman, "Influence and passivity in social media," in Proc. the 20th International Conference Companion on World Wide Web, pp. 1-9, 2010.

[17] O. Hellevik and T. Bjorklund, "Opinion leadership and political extremism," International Journal of Public Opinion Research, vol. 3 , 1991, pp. 157-181.

[18] I. Ajzen and M. Fishbein, Understanding Attitudes and Predicting Human Behavior, Englewood Cliffs, NJ: Prentice Hall, 1980.

[19] E. Katz and P. E. Lazarsfeld, Personal Influence: The Part Played by People in the Flow of Mass Communication, New York: The Free Press, 1955.

[20] E. M. Rogers, Diffusion of Innovations, New York: The Free Press, 1983.

[21] J. Zaller, The Nature and Origins of Mass Opinion, New York: Cambridge University Press, 1992.

[22] E. B. Keller and J. L. Berry, The influentials: One American in ten tells the Other Nine How to Vote, Where to Eat, and What to Buy, New York: Simon \& Schuster, 2003.

[23] G. Weimann, The Influentials: People Who Influence People, Albany, NY: Sate University of New York Pres, 1994.

[24] K. K. Chan and S. Misra, "Characteristics of opinion leaders: A new dimension," Journal of Advertising, vol. 19, 1990, pp. 53-60.

[25] A. Ruvio and A. Shoham, "Innovativeness, exploratory behavior, market mavenship, and opinion leadership: An empirical examination in the Asian context," Psychology and Marketing, vol. 24, pp. 703-722, 2007.

[26] M. P. Venkatraman, "Opinion leaders, adopters, and communication adopters: A role analysis," Psychology and Marketing, vol. 6, pp. 51-68, 1989.

[27] R. F. Baumeister, D. M. Tice, and D. G. Hutton, "Self-presentational motivations and personality differences in self-esteem," Journal of Personality, vol. 57, pp. 547-579, 1989.

[28] M. Rosenberg, Society and the Adolescent Self-Image. Princeton, NJ: Princeton University Press, 1965.

[29] C. Maslach, J. Stapp, and R. Santee, "Individuation: Conceptual analysis and assessment," Journal of Personality and Social Psychology, vol. 49, pp. 729-738, 1985.

[30] V. N. Giri, "Associations of self-esteem with communication style," Psychological Reports, vol. 92, pp. 1089-1090, 2003.

[31] M. R. Leary, "Responses to social exclusion: Social Anxiety, Jealousy, Loneliness, Depression, and Low Self-Esteem," Journal of Social and Clinical Psychology, vol. 9, pp. 221-229, 1990.

[32] P. D. MacIntyre, P. A. Babin, and R. Clement, "Willingness to communicate: antecedents \& consequences," Communication Quarterly, vol. 42, pp. 215-229, 1999.

[33] B. Lyons and K. Henderson, "Opinion leadership in a computer-mediated environment," Journal of Consumer Behavior, vol 4, pp. 319-329, 2005.

[34] S. O'Mahony and F. Ferraro. (2004). Hacking alone? The effects of online and offline participation on open source community leadership. [Online]. http://opensource.mit.edu/papers/omahonyferraro2.pdf

[35] H. Berkman and C. Gilson, Consumer Behavior: Concepts and Strategies, Boston, MA: Kent Publishing Co., 1986.

[36] R. Tannenbaum, I. R. Weschler, and F. Massarik, Leadership and Organization, New York: McGraw-Hill, 1961.

[37] S. M. K. Rao and C. Bhaskaran, "Application of sociometric techniques in identifying opinion leaders in two south Indian villages," Journal of Group Psychotherapy, Psychodrama, and Sociometry, vol. 31, pp. 46-50, 1978.

[38] E. C. Nisbet, "The engagement model of opinion leadership: testing validity within a european context," International Journal of Public Opinion Research, vol. 18, pp. 3-30, 2005.

[39] D. A. Scheufele and D. V. Shah, "Personality strength and social capital: The role of dispositional and informational variables in the production of civic participation," Communication Research, vol. 27, pp. 107-131, 2000 .
[40] W. R. Hazlewood, K. Makice, and W. Ryan, "Twitterspace: A co-developed display using twitter to enhance community awareness," in Proc. the 10th Anniversary Conference on Participatory Design, Bloomington, IN, October 1-4, 2008.

[41] B. Heil and M. Piskorski. (2009). New Twitter Research: Men Follow Men and Nobody Tweets. [Online]. Available: http://blogs.hbr.org/cs/2009/06/new_twitter_research_men_follo.html

[42] J. Yang and G. Stone, "The powerful role of interpersonal communication in agenda setting," Mass Communication and Society, vol. 6, pp. 57-74, 2003.

[43] W. L. Benoit, "Argumentation and credibility appeals in persuasion," Southern Speech Communication Journal, vol. 52, pp. 181-197, 1987.

[44] D. J. Keefe, Persuasion: Theory and Research, Newbury Park, CA Sage, 1990.

[45] R. L. D. Lake and R. Huckfeldt, "Social capital, social networks, and political participation," Political Psychology, vol. 19, pp. 567-584, 1998.

[46] D. A. Scheufele, "Participation as individual choice: Comparing motivational and informational variables and their relevance for participatory behavior," Ph.D. Dissertation, Dept. Comm, Univ. of Wisconsin, Madison, Wisconsin, 1999

[47] H. B. Brosius and G. Weimann, "Who sets agenda? Agenda-setting as a two-step flow," Communication Research, vol. 23, pp. 562-581, 1996.

[48] F. E. Baum, R. A. Bush, C. C. Modra, C. J. Murray, E. M. Cox, K. M. Alexander, and R. C. Potter, "Epidemiology of participation: an Australian community study," Journal of Epidemiology and Community Health, vol. 54, pp. 414-423, 2000.

[49] G. Weimann, "The influential's: Back to the concept of opinion leaders," Public Opinion Quarterly, vol. 55, pp. 267-279, 1991.

[50] A. Vishwanath. "The effect of the number of opinion seekers and leaders on technology attitudes and choices," Human Communication Research, vol. 32, pp. 322-350, 2006

[51] G. M. Wittenbaum, "The bias toward discussing shared information," Communication Research, vol. 27, pp. 379-401, 2000.

[52] C. Shirky, Here Comes Everybody: The Power of Organizing Without Organizations, NY: Penguin Press, 2009.

[53] J. Dimmick, S. Kline, and L. Stafford, "The gratification niches of personal E-mail and the telephone," Communication Research, vol. 27, pp. 227-248, 2000

[54] J. Dimmick, A. Ramirez, T. Wang, and S. F. Lin, "Extending society: The role of personal networks and gratification-utilities in the use of interactive communication media," Journal of New Media \& Society vol. 9, pp. 795-810, 2007.

[55] Z. Papacharissi and A. M. Rubin, "Predictors of internet use," Journal of Broadcasting and Electronic Media, vol. 44, pp. 175-197, 2000.

[56] J. Comm and K. Burge, Twitter Power: How to Dominate Your Market One Tweet at a Time, Hoboken, New Jersey: John Wiley \& Sons, 2009.

[57] J. M. Kishton and K. F. Widaman, "Unidimensional versus domain representative parceling of questionnaire items: An empirical example," Educational and Psychological Measurement, vol. 54, pp. 757-765, 1994

[58] R. S. Landis, D. J. Beal, and P. E. Tesluk, "A comparison of approaches to forming composite measures in structural equation models," Organizational Research Methods, vol. 3, pp. 186-207, 2000.

[59] J. Brockner and A. Hulton, "How to reverse the vicious cycle of low self-esteem: The importance of attentional focus," Journal of Experimental Social Psychologym, vol. 15, pp. 564-578, 1978.

[60] J. D. Campbell and P. J. Fairey, "Effects of self-esteem, hypothetical explanations, and verbalization of expectancies on future performance," Journal of Personality and Social Psychology, vol. 48, pp. 1097-1111, 1985.

[61] D. V. Shah and D. A. Shceufele, "Explicating opinion leadership Nonpolitical dispositions, information consumption, and civic participation," Political Communication, vol. 23, pp. 1-22, 2006.

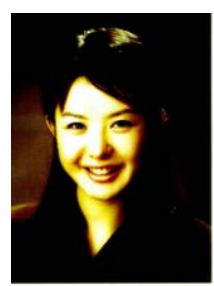

Yoosun Hwang was born in Seoul Korea. Yoosun Hwang obtained her Ph.D. in the field of communication at Yonsei University in Seoul Korea in 2010 received MA majoring in broadcasting and journalism at the Yonsei University, and majored in French language and literature with BA at Yonse University in Seoul Korea in 1996. She had worked at a major public broadcasting company (Korea Broadcasting System) as a News caster then, she had been a Research fellow at Korea Press Foundation. From 2012, she works as an assistant professor at Joongbu University in Chungnam Korea. She has 
published SSCI papers concerning the area of new media and communication; Y. Hwang, "Is communication competence still good for interpersonal media?," Computers in Human Behavior, vol. 27, pp. 924-934, 2011, Y. Hwang and N. Park "Digital divide in social networking sites," International Journal of Mobile Communications, vol. 11, 2013, 446-464 Her current research interests are human computer interaction (HCI) and computer-mediated communication (CMC).
Prof. Hwang is an international committee board of the Cyber Behavior conference. In Korea, she has been devoted herself to several edition boards of the journal papers such as Communication Theory and Korean Journal of Journalism and Communication Studies. She was also a committee member of Cyber Communication Conference in Korea. 